\title{
InFLUENCE OF MOISTURE CONTENT ON THE STRENGTH OF FINGER JOINTS BONDED BEECH WOOD
}

\author{
Alen Ibrisevic, Murco Obucina, Seid Hajdarevic \& Goran Mihulja
}
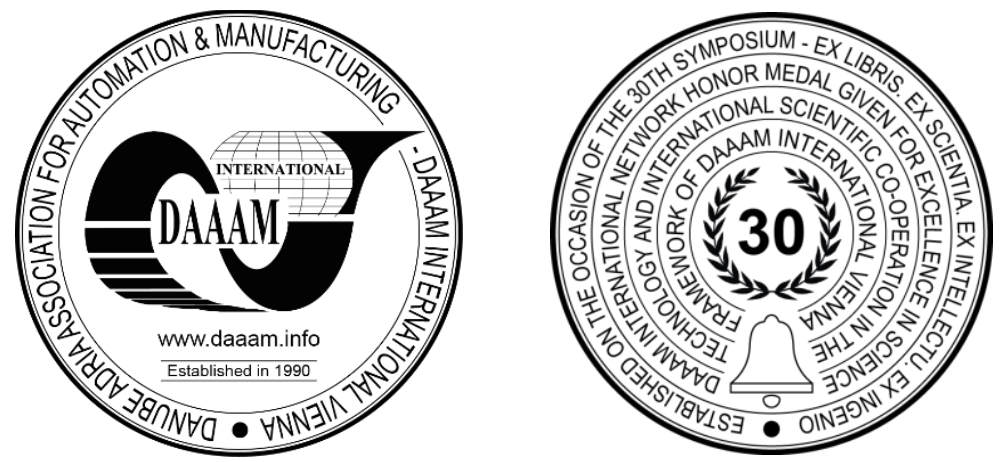

This Publication has to be referred as: Ibrisevic, A[len]; Obucina, M[urco]; Hajdarevic, S[eid] \& Mihulja, G[oran] (2021). Influence of Moisture Content on the Strength of Finger Joints Bonded Beech Wood, Proceedings of the 32nd DAAAM International Symposium, pp.0270-0274, B. Katalinic (Ed.), Published by DAAAM International, ISBN 9783-902734-33-4, ISSN 1726-9679, Vienna, Austria

DOI: $10.2507 / 32$ nd.daaam.proceedings.038

\begin{abstract}
Wood extension is a technological process that has enabled better use of solid wood, reaching longer element lengths and greater stability of solid wood shapes. The paper examines the influence of humidity and adhesive types on the bending strength and modulus of elasticity of the finger joint beech wood. Samples of beech wood of different moisture were lengthwise joined using polyvinyl acetate (PVAC) and polyurethane (PU) adhesive. The bending strength and modulus of elasticity test was performed on a testing machine, and the obtained results were statistically processed by analysis of variance method (ANOVA). The test results showed that when glued in the optimal humidity range of 10$12 \%$, the best results of bending strength and modulus of elasticity are obtained, while with increasing humidity, the mechanical properties of the joint are reduced. Adhesive bonding with PVAC adhesive gives better results of bending strength and modulus of elasticity compared to bonding with PU adhesive.
\end{abstract}

Keywords: bending strength; modulus of elasticity; moisture; adhesive

\section{Introduction}

The lack of quality of technical wood as a raw material for the wood industry is evident and is present all over the world. Therefore, wood extension techniques to be more sophisticated, in order to increase the utilization of sawn timber as well as the dimensional stability and strength of extended wood. The most common way to extend wood is to use a finger joint.

Wood extension is a technological process that has enabled better use of solid wood, reaching longer element lengths and greater stability of solid wood shapes. Wood extension is applied in various constructions and products, such as furniture, construction joinery, various laminated beams and solid boards. Longitudinal joining of wood is most often used in the production of laminated beams [1]. In general, the joint profile and the adhesive used play an important role in the joint strength [2] [6] [7]. The joint profile has the greatest influence on the joint strength. The main geometric characteristics of the finger joint are step (p), length (L), angle (s) and width (T) [9] (Figure 1). The joint strength is a mechanical property that significantly affects the strength of the entire structure. Each structure is exposed to different stresses during operation. The most common stress that occurs in structures is the bending stress [8]. 
Therefore, the bending strength of the finger joint for example in structural finger jointed solid timbers is the most important mechanical property. The joint strength is affected by several factors, primarily the construction of the joint and the adhesive used. The joint strength depends on the cohesion of the adhesive and the internal stresses in the joint [10]. Polyvinyl acetate adhesive (PVAC) and polyurethane (PU) adhesive are commonly used to extend the wood used to make furniture.

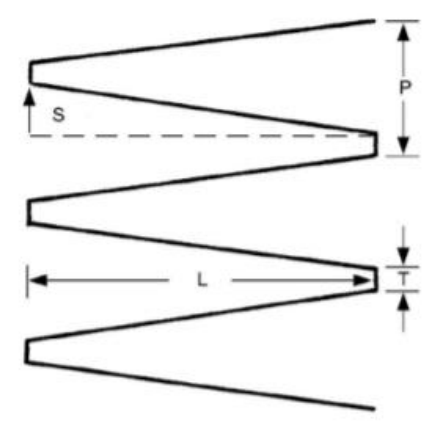

Fig, 1. Geometric characteristics of the finger joint

In addition, climatic factors, such as moisture content and temperature, have a significant impact on product performance [3] [4]. The moisture content in the wood is an important factor that affects the strength of the joint, because some adhesives are affected by the moisture content of the wood [3] [5] [6]. Humidity of wood in wood products intended for indoor use must be dried to moisture content in the range from 8-12\%. If the wood is used for outdoor use, where average air humidity is higher, then the moisture content of the wood used for gluing should also be higher. It is necessary to avoid increased joint stresses due to dimensional changes of the wood.

The aim of this paper is to examine the influence of moisture and type of adhesive on the bending strength and modulus of elasticity of finger joints beech wood.

\section{Materials and methods}

The first part of the experiment involved is making samples. The elements were made of slighty steamed beech wood (Fagus sylvatica L), without visible defects. The dimensions of the elements were $265 \times 42 \times 31 \mathrm{~mm}$, made in a combination of radial and tangential cut. The elements were planned on a four-sided planer "Weinig Profimat 26" with displacement speed of $15 \mathrm{~m} / \mathrm{min}$.

The finger joint elements for longitudinal jointing were made on a "Weinig Grecon Ultra 4" machine. The finger joint profile is shown in Figure 2. The joints were made in the way they are usually done in production of boards with length and width assembly. It is important to notice the tree construction parts/zones of that finger joint. There are three fingers placed in the middle of joint, while in the upper and lower part there is a zone of butt gluing. In this way, the finger joint is hidden, and only a glue line is visible on the product surface. The elements were then bonded with polyvinyl acetate (PVAC) adhesive (AkzoNobel 3311) or with polyurethane (PU) adhesive (Jowatherm-Reactant MR 607.90). Joining was done in such a way that the two individual lamellas were joined together so the final samples measured $530 \times 42 \times 31$ mm (Figure 2).

Totally there was 48 bonded samples, 25 samples were bonded with PVAC, and 23 samples were bonded with PU. Samples were prepared in 5 humidity classes: $9,10,11,12,14 \%$, and wrapped in self-adhesive foil to prevent receiving and releasing of moisture. Moisture content was determinate by the gravimetric method.

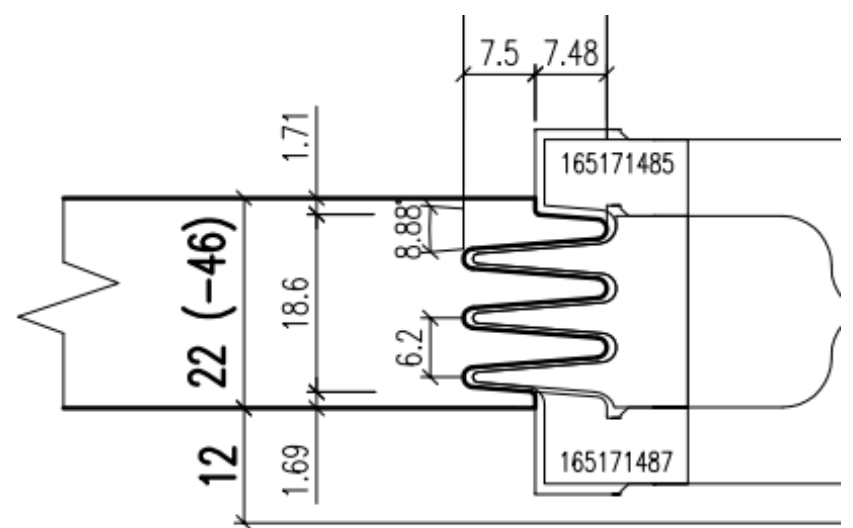

a)

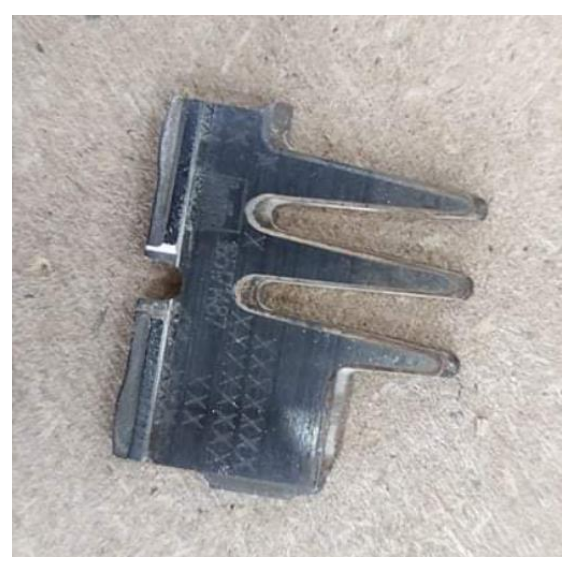

b) 


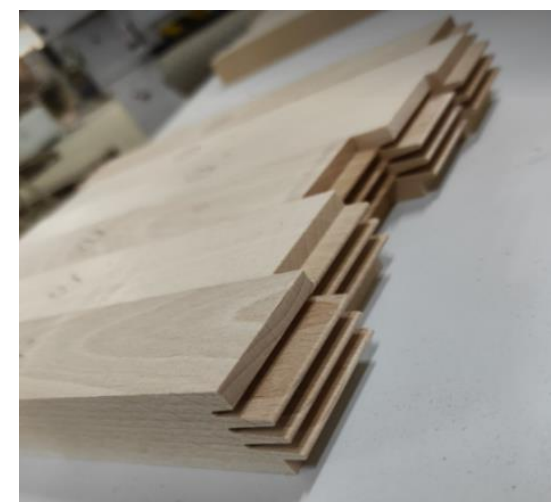

c)

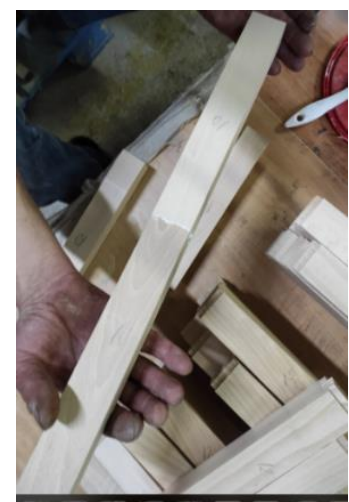

d)

Fig. 2. a) joint geometry, b) tool, c) joint layout, d) test

The second part of the experiment was done in the laboratory located at the Faculty of Mechanical Engineering in Sarajevo. In this phase, the bending strength and modulus of elasticity were tested on samples with different moisture content bonded with PU and PVAC adhesive. The test was performed according to the standard BAS EN 408. The testing was done on "ZWICK + CO.KG Einseingen Uber Ulm Type 1282" machine with connected force and displacement sensors run by CATMAN software (Figure 3). The distance between the supports was $465 \mathrm{~mm}$, while the distance between the presses was $186 \mathrm{~mm}$. The test was performed at a temperature of $20{ }^{\circ} \mathrm{C}$ and a relative humidity of $65 \%$. The obtained results were processed by the analysis of variance method.

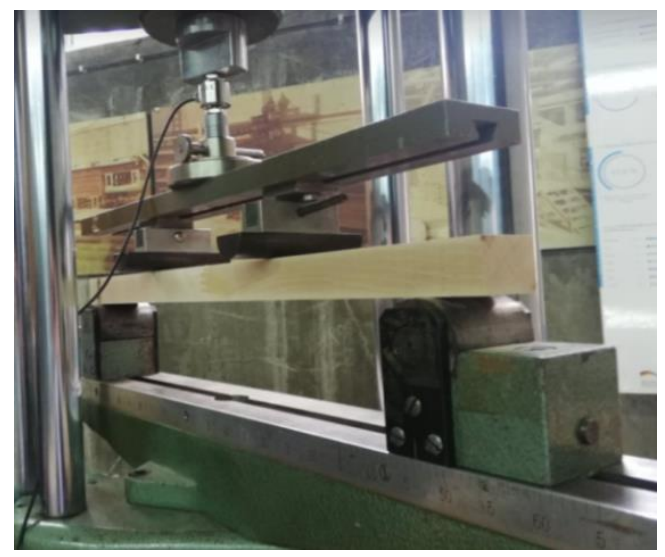

Fig. 3. Bending strength test

\section{Results and discussion}

Results of bending strength according to BAS EN 408 standard and moisture content obtained by gravimetric method are presented in Figure 4.

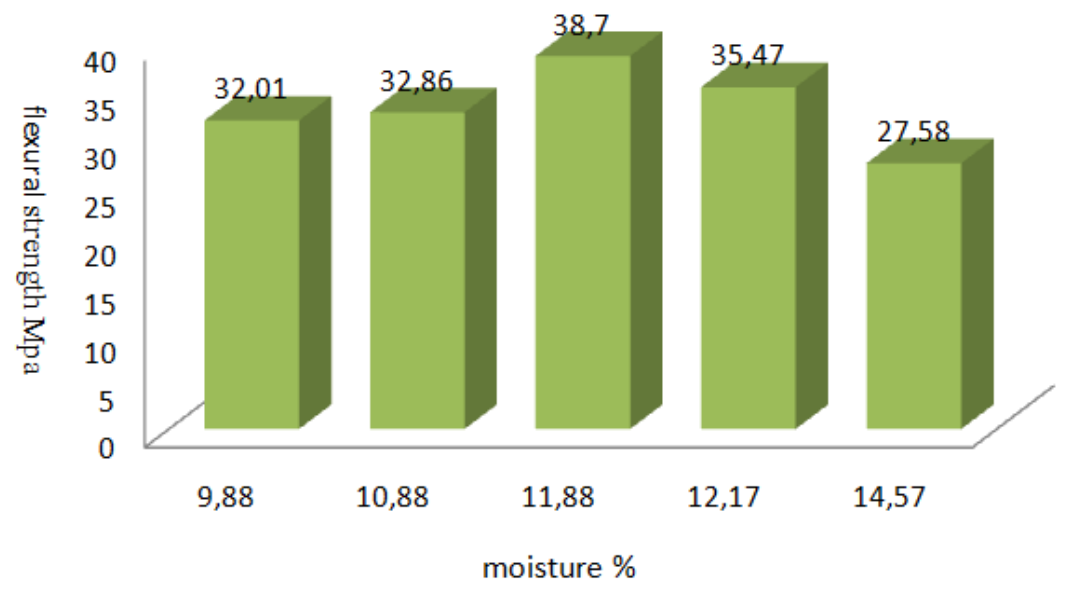

Fig. 4. Bending strength depending on wood moisture (PVAC bonds) 
Results shows that the highest strength is obtained at moisture content of $11.13 \%$, which is in the range for optimal gluing moisture content of $8-12 \%$ according to literature. With an increase in moisture content over $12 \%$, the bending strength decreases. Results were additionally processed by the method of analysis of variance (ANOVA), which showed that there is a statistically significiant difference in bending strength with increasing moisture content (Table 1).

\begin{tabular}{lrrrrr} 
Source & DF & Adj SS & Adj MS & F-Value & P-Value \\
\hline Sample & 4 & 331,4 & 82,85 & 7,71 & 0,001 \\
Error & 20 & 214,9 & 10,75 & & \\
Total & 24 & 546,3 & & &
\end{tabular}

Table 1. Analysis of variance of bending strength of samples with PVAc adhesive

In the case of samples bonded with polyurethane adhesive, the results of bending strength are shown in Figure 5. Figure 5 shows that the highest bending strength is present in samples with a moisture content of $10.47 \%$. It is also visible that best results are obtained in the limits of optimal moisture content of $8-12 \%$, while with the increase of moisture content over $12 \%$, there is a decrease in bending strength. The results were additionally processed by the method of analysis of variance (Table 2), which shows that there is a statistically significant difference between individual samples.

\begin{tabular}{lrrrrr} 
Source & DF & Adj SS & Adj MS & F-Value & P-Value \\
\hline Sample & 4 & 191,43 & 47,857 & 8,92 & 0,000 \\
Error & 18 & 96,57 & 5,365 & & \\
Total & 22 & 288,00 & & &
\end{tabular}

Table 2. Analysis of variance of bending strength for samples bonded with PU adhesive

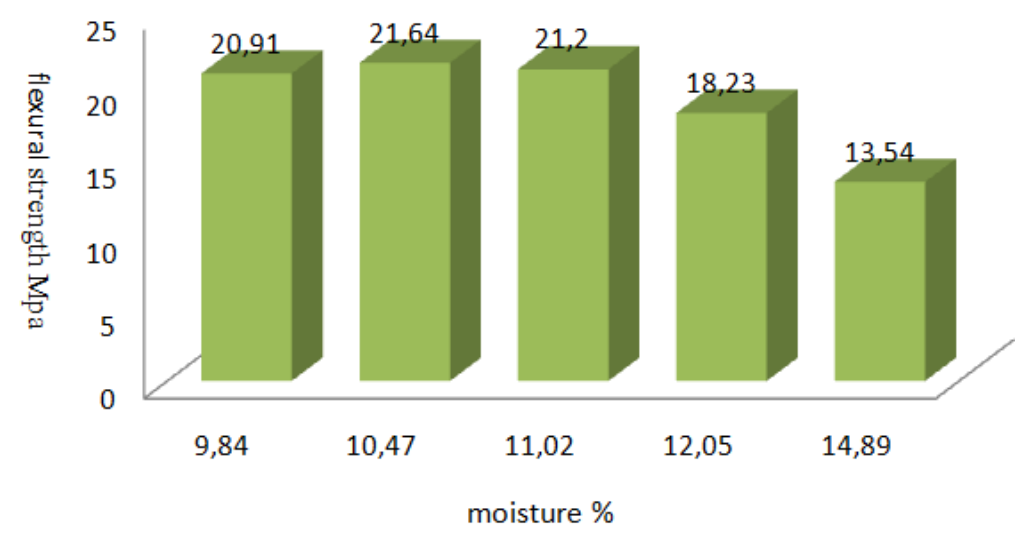

Fig. 5. Bending strength depending on wood moisture (PU bonds)

Based on the presented results, it is evidently that the samples bonded with PVAC adhesive have a higher bending strength compared to the samples bonded with PU adhesive. The maximum bending strength of PVAC samples are $44 \%$ higher than the maximum bending strength of PU samples. Based on the graph and data processing, it can be concluded that in the same moisture range, both PVAC and PU adhesives give the best bending strength results (moisture around 11\%). Table 3 gives comparative analyses of bending strength and modulus of elasticity for samples bonded with PVAC and PU adhesives. It can be noticed that, the values of bending strength are higher in samples with PVAC adhesive compared to PU adhesive. It is also evident that the type of adhesive does not affect the change of the modulus of elasticity, because the values of the modulus of elasticity are approximately the same regardless of the type of adhesive. The result of the influence of the moisture content on modulus of elasticity largely coincides with the result of its influence on bending strengths.

\begin{tabular}{|l|l|r|r|r|r|r|}
\hline Adhesive & Moisture (\%) & 9 & 10 & 11 & 12 & 14 \\
\hline PVAc & Bending strength (Mpa) & 32,01 & 32,86 & 38,7 & 35,47 & 27,58 \\
\hline & Modulus of elasticity (GPa) & 1,93 & 2,12 & 2,65 & 2,78 & 2,41 \\
\cline { 2 - 7 } & & & & & & \\
\hline PU & Bending strength (Mpa) & 20,91 & 21,64 & 21,2 & 18,23 & 13,54 \\
\hline & Modulus of elasticity (GPa) & 2,18 & 2,36 & 2,6 & 2,77 & 2,59 \\
\hline
\end{tabular}

Table 3. Comparative values of bending strength and modulus of elasticity 
Experimental testing of bending strength and modulus of elasticity yielded small values general. The values obtained are probably the result of the joint profile. Practically, only three fingers were made in by the thickness value, and a large gluing surface was not achieved. On the other hand, the area of the butt adhesive bonding is quite large compared to total bonding surface, and consider it low bonding strength it expected that it is going to is reflected in the lower value of the bending strength and modulus of elasticity of complete joint.

\section{Conclusion}

Testing the bending strength on samples with PVAC and PU adhesive at different wood moisture content showed that the moisture in wood greatly affects the joint strength. Wood glued within the optimum humidity range of 10-12\% showed the highest values of bending strength. When the moisture content increases over $12 \%$, the strength of the joint decreases.

Finger joints bonded with PVAC adhesive, have a higher joint strength compared to elements bonded with PU adhesive with the difference in strength of $44 \%$. If we take into account that PVAC adhesive has a much lower price compared to PU adhesive, then we come to the conclusion that finger joints with PVAC adhesive gives a more competitive product. The value of the modulus of elasticity is not affected by the type of adhesive, while moisture affects it in the same way as the bending strength. The highest values of the modulus of elasticity are obtained at a wood moisture content of $10-12 \%$, while with an increase in humidity over $12 \%$, the modulus of elasticity changes.

The results obtained small values of bending strength and modulus of elasticity than expected. These small values are for the most part influenced by geometry (joint profile).

\section{References}

[1] Frangi, A; Bertocchi, M ; Clauss, S; Niemz, P. (2012). Mechanical behaviour of finger joints at elevated temperatures, Wood Science and Technology, Vol. 46, No.5, 793-812, DOI: 10.1007/s00226-011-0444-9

[2] Kumar, V.S.K; Sharma, C.M; Gupta, S (2015). Compression and flexular properties of finger jointed mango wood sections, Maderas-Ciencia y Technologia, Vol.17, No.1, 151-160, DOI: 10.4067/S0718-221X2015005000015

[3] Liu, J; Yue, K; Wang, F; Wu, JH; Tang, ZQ;Chen, ZJ; Lu, WD; Liu, WQ (2020). Effects of Moisture Content on Lap-shear, Bending, and Tensile Strength of Lap-jointed and Finger-Jointed Southern Pine using Phenol Resorcinol Formaldehyde and Melamine Urea Formaldehyde, BioResources, Vol.15, No.2, 3534-3544, DOI: 10.15376/biores.15.2.3534-3544

[4] Liu, J; Yue, K; Xu, LQ; Wu, JH; Chen, ZJ; Wang, L; Liu, WQ; Lu, WD. (2020).Bonding performance of melamine-urea-formaldehyde and phenol-resorcinol- formaldehyde adhesive glulams at elevated temperatures, International Journal of Adhesion and Adhesives, Vol. 98. DOI10.1016/j.ijadhadh.2019.102500

[5] Bomba, J., Šedivka, P., Böhm, M., and Devera, M. (2014). Influence of moisture content on the bond strength and water resistance of bonded wood joints, BioResources Vol. 9, No.3, 5208-5218. DOI: 10.15376/biores.9.3.52085218

[6] Máchová, E., Langová, N., Réh, R., Joščák, P., Krišt’ák, L., Holouš, Z., Igaz, R., and Hitka, M. (2019). Effect of moisture content on the load carrying capacity and stiffness of corner wood-based and plastic joints, BioResources, Vol.14, No.4, 8640-8655. DOI: 10.15376/biores.14.4.8640-8655

[7] Fortuna, B; Azinovic, B; Plos, M; Suligoj, T; Turk, G. (2020). Tension strength capacity of finger joined beech lamella, EUROPEAN JOURNAL OF WOOD AND WOOD PRODUCTS, Vol.78, No.5, 985-994, DOI 10.1007/s00107-020-01588-9

[8] Ibrisevic,A; Obucina,M; Hajdarevic,S.(2019). Effect of Particleboard Coating on Flexual Strength and Modulus of Elasticity, Proceedings of the 30th International DAAAM Symposium "Intelligent Manufacturing \& Automation", Zadar, ISBN 978-3-902734-xx-x, ISSN 1726-9679, Katalinic, B. (Ed.), Published by DAAAM International, Vienna, Austria, DOI: 10.2507/30th.daaam.proceedings.124

[9] Barboutiss, I; Vassiliou, V.(2019). Strength of finger-jointed beech wood (Fagus sylvatica) constructed with small finger lengths, ProLigno, Vol.9, No.4, 359-364, ISSN 2069-7430

[10] Obucina, M; Gondzic, E; Smajic, S.(2014). The Influence of Amount of Layer on the Bending Strenght by Longitudinal Finger-Jointing Wood Elements, Procedia Engineering. Vol.69, 1094-1099 